\title{
Detection
}

\section{of metallo- $\beta$-lactamases-encoding genes among clinical isolates of Pseudomonas aeruginosa in a tertiary care hospital, Kathmandu, Nepal}

\author{
Mahesh Acharya ${ }^{1 *}$, Prabhu R. Joshi ${ }^{1}$, Kamal Thapa ${ }^{2}$, Rajan Aryal ${ }^{3}$, Trishna Kakshapati ${ }^{4}$ and Supriya Sharma ${ }^{1}$
}

\begin{abstract}
Objectives: This study was carried out to determine the prevalence of metallo- $\beta$-lactamases (MBLs) producing Pseudomonas aeruginosa in imipenem-nonsusceptible isolates and to detect MBL-encoding genes among MBLs-positive isolates.

Results: Metallo- $\beta$-lactamases production was detected in $68.6 \%$ isolates of $P$. aeruginosa with reduced susceptibility to imipenem. The bla $a_{V I M-2}$ gene was detected in $75 \%$ isolates and bla $a_{\text {IMP-1 }}$ was detected in $25 \%$ isolates. All MBLspositive isolates were multidrug resistant with a high level of resistance to imipenem (MIC 16 to $\geq 32 \mu \mathrm{g} / \mathrm{ml}$ ), meropenem (MIC 16 to $\geq 32 \mu \mathrm{g} / \mathrm{ml}$ ), and ceftazidime (MIC 64 to $\geq 512 \mu \mathrm{g} / \mathrm{ml}$ ). All MBL-positive isolates were susceptible (MIC $\leq 2 \mu \mathrm{g} / \mathrm{ml}$ ) to colistin. We found high prevalence of MBL-producing $P$. aeruginosa. To our knowledge this is the first report of detection of bla $a_{\mathrm{VIM}-2}$ and bla $a_{\mathrm{IMP}-1}$ in P. aeruginosa from Nepal. This indicates the need for awareness to prevent the spreading of these resistant isolates in hospital setting.
\end{abstract}

Keywords: Metallo- $\beta$-lactamases, Imipenem-nonsusceptible, bla $a_{\mathrm{VIM}-2,}$ bla $a_{\mathrm{IMP}-1}$

\section{Introduction}

Pseudomonas aeruginosa is a Gram-negative, non-fermentative organism found in diverse environmental settings [1]. It is an opportunistic pathogen, causing serious infection in patients with weakened immune systems [2]. This organism is generally intrinsically resistant to a wide variety of antimicrobial agents as well as it has the capacity to develop resistance by mutation or acquisition of foreign resistance genes against different antibiotic classes [3]. Carbapenem, including imipenem, meropenem and doripenem are often used as a last resort for treatment of infections caused by P. aeruginosa and other Gramnegative bacteria $[4,5]$. However, carbapenem-resistant

\footnotetext{
*Correspondence: maheshacharya045@gmail.com

${ }^{1}$ Central Department of Microbiology, Tribhuvan University, Kirtipur, Kathmandu, Nepal

Full list of author information is available at the end of the article
}

P. aeruginosa has become prevalent globally [6, 7]. Carbapenem resistance may arise in $P$. aeruginosa via OprD channel deficiencies, up-regulation of efflux pumps and production of various kinds of carbapenemases, including serine $\beta$-lactamases of Ambler classes $A$ and $D$ and metallo- $\beta$-lactamases (MBLs) of Ambler class B [8].

Among various mechanism of resistance for carbapenem in P. aeruginosa, production of MBLs is of particular concern because of their rapid spread, potent carbapenemase activity, resistance to $\beta$-lactamase inhibitors and ability to hydrolyze all $\beta$-lactam antibiotics with the exception of aztreonam [9]. Furthermore, MBLs encoding genes are usually located on integrons, the mobile genetic elements that also carry genes encoding for resistance to aminoglycoside and other antibiotics resulting in multidrug resistance (MDR) [10]. 
Several types of MBLs, such as IMP, VIM, SPM, GIM, AIM, FIM and NDM and their variants have been identified in P. aeruginosa [11-13]. Among them, variants of VIM and IMP types such as $b l a_{\mathrm{VIM}-1}, b l a_{\mathrm{VIM}-2}, b l a_{\mathrm{IMP}-1}$ and $b l a_{\mathrm{IMP}-2}$ are the most commonly found MBL genes in $P$. aeruginosa and responsible for many nosocomial outbreaks [9].

Although, production of MBLs in clinical isolates is a serious therapeutic problem, so far limited information is available on MBL production in P. aeruginosa clinical isolates from Nepal. The objectives of this study were to determine the prevalence of MBL producing $P$. aeruginosa and to detect MBL-encoding genes $\left(b l a_{\mathrm{VIM}-1}\right.$, $b l a_{\mathrm{VIM}-2}, b l a_{\mathrm{IMP}-1}$ and $\left.b l a_{\mathrm{IMP}-2}\right)$.

\section{Main text \\ Methods \\ Bacterial isolates}

Clinical specimens submitted for routine culture and antibiotic susceptibility testing from hospitalized patients during the period of October 2015 to July 2016, at the microbiology laboratory of the Annapurna Neurological Institute and Allied Sciences were processed. $P$. aeruginosa were isolated and identified based on conventional biochemical test [14]. All $P$. aeruginosa isolates were screened for reduced susceptibility to imipenem $(\mathrm{MIC} \geq 8 \mu \mathrm{g} / \mathrm{ml}$ ) by E-test strips.

\section{Confirmation of MBL production and antimicrobial susceptibility testing}

All the isolates that showed reduced susceptibility to imipenem were tested for MBL production by the imipenem-EDTA disk diffusion test [15]. Susceptibility testing of the isolates were performed by disk diffusion according to the Guidelines of Clinical and Laboratory Standard Institute (CLSI) [16]. The following antimicrobial agents were used: ceftazidime $(30 \mu \mathrm{g})$, imipenem $(10 \mu \mathrm{g})$, meropenem $(10 \mu \mathrm{g})$, ciprofloxacin $(5 \mu \mathrm{g})$, aztreonam $(30 \mu \mathrm{g})$, amikacin $(30 \mu \mathrm{g})$, gentamicin $(10 \mu \mathrm{g})$, piperacillin $(100 \mu \mathrm{g})$, piperacillin-tazobactam $(100 / 10 \mu \mathrm{g})$ and cefepime $(30 \mu \mathrm{g})$. MIC of imipenem, meropenem, ceftazidime and colistin were determined by E-test strips (according to manufacturers instruction) and agar dilution method on all MBLs-producing isolates [16]. All the antibiotics and E-test strips were procured from $\mathrm{Hi}$ media, India. P. aeruginosa ATCC 27853 was used as a quality control in the susceptibility testing.

\section{Detection of MBL encoding genes by multiplex PCR}

Total DNAs of MBL-positive P. aeruginosa isolates were extracted using a boiling method, briefly; $3-5$ colonies from an overnight culture grown on Mueller-Hinton agar (Hi-media, India) were transferred to $300 \mu \mathrm{l}$ of nuclease-free water and boiled at $100{ }^{\circ} \mathrm{C}$ for $10 \mathrm{~min}$. After centrifugation at $12,000 \times g$ for $5 \mathrm{~min}$, the supernatant was used as a source of template for amplification. Multiplex PCR amplification of MBL genes including $b l a_{\mathrm{VIM}-1}, b l a_{\mathrm{VIM}-2}, b l a_{\mathrm{IMP}-1}$ and $b l a_{\mathrm{IMP}-2}$ were performed (5 Prime/02, Bibby Scientific, UK) [17]. Amplification was carried out with the following thermal cycling conditions: initial denaturation at $95{ }^{\circ} \mathrm{C}$ for $5 \mathrm{~min}$ and 36 cycles of amplification consisting of $40 \mathrm{~s}$ at $94{ }^{\circ} \mathrm{C}, 40 \mathrm{~s}$ at $52{ }^{\circ} \mathrm{C}, 50 \mathrm{~s}$ at $72{ }^{\circ} \mathrm{C}$, with $5 \mathrm{~min}$ at $72{ }^{\circ} \mathrm{C}$ for the final extension.

Pseudomonas aeruginosa NCTC 13437 producing bla $_{\mathrm{VIM}}$ and Escherichia coli NCTC 13476 producing $b l a_{\mathrm{IMP}}$ kindly provided by Prof. Neil Woodford from Public Health England were used as positive control and $P$. aeruginosa ATCC 27853 were used as negative control.

\section{Results}

A total of $98 P$. aeruginosa were obtained during the study period. Of the total isolates, only 35 (35.7\%) isolates showed reduced susceptibility to imipenem (MIC $\geq 8 \mu \mathrm{g}$ / $\mathrm{ml})$. Of the 35 isolates with reduced susceptibility to imipenem, 24 (68.6\%) were positive for MBL production by the imipenem-EDTA disk diffusion test. Eighteen isolates (75\%) were $b l a_{\mathrm{VIM}-2}$ positive and $6(25 \%)$ were $b l a_{\mathrm{IMP}-1}$ positive. In this study, $b l a_{\mathrm{VIM}-1}$ and $b l a_{\mathrm{IMP}-2} \mathrm{MBL}$ allele were not detected. MBL-positive isolates were from intensive care unit (ICU) 14 (58.4\%) and 10 (41.6\%) were from general ward patients.

All MBL positive isolates were susceptible $(\mathrm{MIC} \leq 2 \mu \mathrm{g} / \mathrm{ml})$ to colistin and majority of MBLproducing isolates were also susceptible to aztreonam (62.5\%), whereas $24(100 \%)$ were resistant to meropenem, piperacillin, ceftazidime and cefepime. All MBL-positive isolates had high resistance rates to ciprofloxacin (75\%), amikacin (83.4\%) gentamicin (91.7\%) and piperacillintazobactam (95.8\%). Using Magiorakos et al. definitions for multidrug-resistant and panresistant $P$. aeruginosa [18], all MBL positive isolates were multidrug resistant with a high level of resistant to imipenem (MIC 16 to $\geq 32 \mu \mathrm{g} / \mathrm{ml}$ ), meropenem (MIC 16 to $\geq 32 \mu \mathrm{g} / \mathrm{ml}$ ), and ceftazidime (MIC 64 to $\geq 512 \mu \mathrm{g} / \mathrm{ml}$ ). Characteristics of MBL-producing $P$. aeruginosa are shown in (Table 1).

\section{Discussion}

Our study showed that $68.6 \%(24 / 35)$ isolates of P. aeruginos $a$ with reduced susceptibility to imipenem were MBL producers. This finding was higher than those reported in the previous study from Nepal [19], indicating that MBL-producing $P$. aeruginosa is increasing. High prevalence of MBL producing $P$. aeruginosa was also detected in India, a neighboring country of Nepal (69.8\%) [20], Taiwan (55.1\%) [21], and Egypt (68.7\%) [22]. The reduced 
Table 1 Characteristics of metallo- $\beta$-lactamases producing $P$. aeruginosa

\begin{tabular}{|c|c|c|c|c|c|c|c|c|}
\hline \multirow[t]{2}{*}{ Isolate } & \multirow[t]{2}{*}{ Hospital site } & \multirow[t]{2}{*}{ Sample } & \multirow[t]{2}{*}{$b l a_{\mathrm{VIM}-2}$} & \multirow[t]{2}{*}{$b l a_{\text {IMP-1 }}$} & \multicolumn{4}{|c|}{$\operatorname{MICs}(\mu \mathrm{g} / \mathrm{ml})$} \\
\hline & & & & & IPM & MRP & CAZ & $\mathrm{CL}$ \\
\hline 1 & ICU & Sputum & + & - & 16 & 32 & 256 & 1 \\
\hline 2 & ICU & Sputum & + & - & 64 & 64 & 512 & 1 \\
\hline 3 & GW & Urine & + & - & 128 & 128 & 512 & 0.5 \\
\hline 4 & ICU & Sputum & - & + & 128 & 128 & 256 & 2 \\
\hline 5 & GW & Urine & + & - & 128 & 256 & 512 & 2 \\
\hline 6 & GW & Urine & + & - & 16 & 16 & 512 & 0.5 \\
\hline 7 & GW & Sputum & - & + & 256 & 128 & 512 & 2 \\
\hline 8 & ICU & Pus/wound swab & - & + & 64 & 64 & 512 & 1 \\
\hline 9 & GW & Urine & - & + & 128 & 64 & 64 & 2 \\
\hline 10 & GW & Sputum & - & + & 128 & 64 & 128 & 0.25 \\
\hline 11 & $\mathrm{ICU}$ & Tracheal aspirates & + & - & 256 & 64 & 128 & 1 \\
\hline 12 & ICU & Urine & + & - & 256 & 64 & 256 & 1 \\
\hline 13 & ICU & Sputum & + & - & 128 & 64 & 256 & 1 \\
\hline 14 & ICU & Sputum & + & - & 32 & 32 & 512 & 0.25 \\
\hline 15 & ICU & Pus/wound swab & + & - & 64 & 32 & 128 & 2 \\
\hline 16 & GW & Urine & + & - & 128 & 128 & 256 & 2 \\
\hline 17 & $\mathrm{ICU}$ & Sputum & + & - & 128 & 128 & 512 & 0.5 \\
\hline 18 & ICU & Sputum & + & - & 128 & 128 & 256 & 2 \\
\hline 19 & GW & Pus/wound swab & + & - & 64 & 64 & 512 & 2 \\
\hline 20 & GW & Urine & + & - & 256 & 128 & 128 & 2 \\
\hline 21 & GW & Sputum & + & - & 16 & 32 & 256 & 1 \\
\hline 22 & ICU & Urine & - & + & 128 & 32 & 64 & 1 \\
\hline 23 & ICU & Tracheal aspirates & + & - & 256 & 256 & 512 & 2 \\
\hline 24 & $\mathrm{ICU}$ & Sputum & + & - & 128 & 256 & 256 & 1 \\
\hline
\end{tabular}

ICU intensive care unit, GW general ward, MIC minimum inhibitory concentration, IPM imipenem, MRP meropenem, CAZ ceftazidime, CL colistin

imipenem susceptibilities in MBL-negative isolates might be due to other mechanisms such as deficiency in porin channel combined with production of AmpC $\beta$-lactamases [8].

In the present study, bla $a_{\mathrm{VIM}-2}$ was the most commonly detectable genes among the different MBL genes analyzed; $75 \%$ of MBL-positive isolates carried $b l a_{\mathrm{VIM}-2}$. Only $25 \%$ of MBL-positive isolates carried $b l a_{\mathrm{IMP}-1}$. This finding was supported by result of previous studies from around the world demonstrating $b l a_{\mathrm{VIM}-2}$ as the most common MBL genes responsible for reduced susceptibility to imipenem in $P$. aeruginosa and pose greatest clinical threat [23]. bla $a_{\mathrm{VIM}-2}$ gene is associated with many nosocomial outbreaks due to MBL-producing $P$. aeruginosa [24]. Although, less than VIM-2 type, IMP-1 also have been reported from worldwide [25]. Due to the high mortality rate of infections caused by MBL-producing $P$. aeruginosa, their presence in hospital setting is of great concern. To evaluate the threat of MBL-producing $P$. aeruginosa and its associated risk factors, well-designed multicentre epidemiological studies are urgently required.
In this study, all MBL-producing isolates were MDR, leaving the limited treatment option. Based on the in vitro testing; the most effective antibiotic against MBL-producing isolates were colistin (100\% susceptible, MIC $\leq 2 \mu \mathrm{g} / \mathrm{ml}$ ), followed by aztreonam (62.5\% susceptible). The existence of the MBL genes on integrons together with other resistance gene makes the MBLpositive isolates MDR [10]. Due to the limited treatment option (potentially toxic polymyxin B and colistin) for the infections caused by MBL-producing isolates and the mobile nature of MBL, early detection of MBL-producing isolates in hospital setting is necessary to initiate the appropriate infection control procedure to avoid the spread of these multidrug resistant isolates.

Aztreonam is stable against MBLs [10]; however in this study $37.5 \%$ of the MBL-producing isolates were resistant to aztreonam, suggesting a possible association with other resistance mechanisms such as AmpC type $\beta$-lactamases or ESBLs [1].

Many studies have shown that intensive care unit is the epicenter and the main source of amplification and dissemination of antimicrobial resistance [26], a finding 
that was also observed in this study among the $24 \mathrm{MBL}-$ positive isolates; 14 (58.4\%) were isolated from ICU while $10(41.6 \%)$ were from general ward patients. Since more than $50 \%$ of MBL-producing P. aeruginosa isolates have been recovered from ICU, it is highly probable that it might be a clonal spread. Unfortunately, because of some limitations, such as lack of more equipped laboratory, we were not able to do genotypic comparisons of the isolates.

\section{Conclusion}

In conclusion, our study showed the presence of $b l a_{\mathrm{VIM}-2}$ and $b l a_{\mathrm{IMP}-1}$ producing $P$. aeruginosa for the first time in Nepal that underscores the necessity of screening all imipenem-resistant isolates for MBL production and implementation of infection control programs to prevent spread of such organisms.

\section{Limitations}

- The study was unable to determine whether these MBL genes are transferable or not.

- The study was unable to investigate other MBLencoding genes such as NDM-1.

- Due to the lack of laboratory equipment, we could not perform genotypic comparisons of the isolates.

\section{Abbreviations}

ATCC: American Type Culture Collection; CAZ: ceftazidime; CL: colistin; EDTA: ethylenediaminetetraacetic acid; GW: general ward; ICU: intensive care unit; IPM: imipenem; MBL: metallo- $\beta$-lactamase; MDR: multidrug resistance; MIC: minimum inhibitory concentration; MRP: meropenem; NCTC: National Collection of Type Cultures; OPD: out patients department.

\section{Authors' contributions}

MA and PRJ designed the study, collected data, analyzed the data and prepared the manuscript, KT and RA collected data, TK and SS supervised the study. All authors read and approved the final manuscript.

\section{Author details}

${ }^{1}$ Central Department of Microbiology, Tribhuvan University, Kirtipur, Kathmandu, Nepal. ${ }^{2}$ Kathmandu College of Science and Technology, Tribhuvan University, Kathmandu, Nepal. ${ }^{3}$ Kantipur College of Medical Sciences, Tribhuvan University, Kathmandu, Nepal. ${ }^{4}$ Annapurna Neurological Institute and Allied Sciences, Kathmandu, Nepal.

\section{Acknowledgements}

This work is a part of Master's thesis that has been supported by Central Department of Microbiology, Tribhuvan University and Annapurna Neurological Institute and Allied Sciences. We thank the staff of both institutes and Nepal Health research Council for ethical clearance. We also acknowledge Prof. Neil Woodford, Public Health England for providing control strains.

\section{Competing interests}

The authors declare that they have no competing interests.

\section{Availability of data and materials}

The raw data can be made available to the interested researchers by the authors of this article if requested.

\section{Consent to publish}

Not applicable.
Ethics of approval and consent to participate

Ethical approval was obtained from the Ethical Review Board of Nepal Health Research Council (NHRC) (Reg. 27/2015). Since the clinical specimens submitted for routine bacteriological testing were processed, consent to participate is not applicable.

Funding

To conduct this study no fund was obtained from any sources.

\section{Publisher's Note}

Springer Nature remains neutral with regard to jurisdictional claims in published maps and institutional affiliations.

Received: 9 October 2017 Accepted: 5 December 2017

Published online: 08 December 2017

\section{References}

1. Lister PD, Wolter DJ, Hanson ND. Antibacterial-resistant Pseudomonas aeruginosa: clinical impact and complex regulation of chromosomally encoded resistance mechanisms. Clin Microbiol Rev. 2009;22:582-610.

2. Coggan KA, Wolfgang MC. Global regulatory pathways and cross-talk control Pseudomonas aeruginosa environmental lifestyle and virulence phenotype. Curr Issues Mol Biol. 2012;14:47-70.

3. Strateva T, Yordanov D. Pseudomonas aeruginosa - a phenomenon of bacterial resistance. J Med Microbiol. 2009;58:1133-48.

4. Giamarellou H, Poulakou G. Multidrug-resistant Gram-negative infections: what are the treatment options? Drugs. 2009;69:1879-901.

5. Riera E, Cabot G, Mulet X, Garcia-Castillo M, del Campo R, Juan C, Canton $\mathrm{R}$, Oliver A. Pseudomonas aeruginosa carbapenem resistance mechanisms in Spain: impact on the activity of imipenem, meropenem and doripenem. J Antimicrob Chemother. 2011;66:2022-7.

6. Nagao M, linuma Y, Igawa J, Saito T, Yamashita K, Kondo T, Matsushima S, Takakura A, Takaori-Kondo A, Ichiyama S. Control of an outbreak of carbapenem-resistant Pseudomonas aeruginosa in a haematooncology unit. J Hosp Infect. 2011;79:49-53.

7. Livermore DM. Has the era of untreatable infections arrived? J Antimicrob Chemother. 2009;64(Suppl 1):i29-36.

8. Quale J, Bratu S, Gupta J, Landman D. Interplay of efflux system, ampC, and oprD expression in carbapenem resistance of Pseudomonas aeruginosa clinical isolates. Antimicrob Agents Chemother. 2006;50:1633-41.

9. Cornaglia G, Giamarellou H, Rossolini GM. Metallo-beta-lactamases: a last frontier for beta-lactams? Lancet Infect Dis. 2011;11:381-93.

10. Walsh TR. Clinically significant carbapenemases: an update. Curr Opin Infect Dis. 2008;21:367-71.

11. Gupta V. Metallo- $\beta$-lactamases in Pseudomonas aeruginosa and Acinetobacter species. Expert Opin Investig Drugs. 2008;17:131-43.

12. Pollini S, Maradei S, Pecile P, Olivo G, Luzzaro F, Docquier JD, Rossolini GM. FIM-1, a new acquired metallo $\beta$-lactamase from a Pseudomonas aeruginosa clinical isolate from Italy. Antimicrob Agents Chemother. 2013:57:410-6.

13. Jovcic B, Lepsanovic Z, Suljagic V, Rackov G, Begovic J, Topisirovic L, Kojic M. Emergence of NDM-1 metallo- $\beta$-lactamase in Pseudomonas aeruginosa clinical isolates from Serbia. Antimicrob Agents Chemother. 2011;55:3929-31.

14. Forbes BA, Sahm DF, Weissfeld AS. Bailey and Scott's diagnostic microbiology. 11 th ed. St. Louis: Mosb Inc; 2002. p. 389-97.

15. Yong D, Lee K, Yum JH, Shin HB, Rossolini GM, Chong Y. Imipenem-EDTA disk method for differentiation of metallo-beta-lactamase-producing clinical isolates of Pseudomonas spp. and Acinetobacter spp. J Clin Microbiol. 2002;40:3798-801.

16. Clinical and Laboratory Standards Institute. Performance standards for antimicrobial susceptibility testing; twenty-fourth informational supplement, M100-S24. Wayne: Clinical and Laboratory Standards Institute; 2014 
17. Shibata N, Doi Y, Yamane K, Yagi T, Kurokawa H, Shibayama K, Kato H, Kai K, Arkawa Y. PCR typing of genetic determinants for metallo- $\beta$-lactamase and integrase carried by Gram-negative bacteria isolated in Japan, with focus on the class 3 integron. J Clin Microbiol. 2003;41:5407-13.

18. Magiorakos AP, Srinivasan A, Carey RB, Carmeli Y, Falagas ME, Giske CG, Harbarth S, Hindler JF, Kahlmeter G, Olsson-Liljequist B, Paterson DL, Rice LB, Stelling J, Struelens MJ, Vatopoulos A, Weber JT, Monnet DL. Multidrug-resistant, extensively drug-resistant and pandrug-resistant bacteria: an international expert proposal for interim standard definitions for acquired resistance. Clin Microbiol Infect. 2012;18:268-81.

19. Thapa P, Bhandari D, Shrestha D, Parajuli H, Chaudhary P, Amatya J, Amatya R. A hospital based surveillance of metallo-beta-lactamase producing gram negative bacteria in Nepal by imipenem-EDTA disk method. BMC Res Notes. 2017;10:322

20. Gupta V, Sidhu S, Chander J. Metallo- $\beta$-lactamase producing nonfermentative Gram-negative bacteria: an increasing clinical threat among hospitalized patients. Asian Pac J Trop Med. 2012;5:718-21.

21. Lee MF, Peng CF, Hsu HJ, Chen YH. Molecular characterisation of the metallo- $\beta$-lactamase genes in imipenem resistant Gram-negative bacteria from a university hospital in southern Taiwan. Int J Antimicrob Agents. 2008;32:475-80.

22. Zafer MM, Al-Agamy MH, El-Mahallawy HA, Amin MA, Ashour SED. Dissemination of VIM-2 producing Pseudomonas aeruginosa ST233 at tertiary care hospitals in Egypt. BMC Infect Dis. 2015;15:122-9.

23. Pitout JDD, Revathi G, Chow BL, Kabera B, Kariuki S, Nordmann P, Poirel L. Metallo- $\beta$-lactamase-producing Pseudomonas aeruginosa isolated from a large tertiary centre in Kenya. Clin Microbiol Infect. 2008;14:755-9.

24. Elias J, Schoen C, Heinze G, Valenza G, Gerharz E, Riedmiller H, Vogel U Nosocomial outbreak of VIM-2 metallo- $\beta$-lactamase-producing Pseudomonas aeruginosa associated with retrograde urography. Clin Microbiol Infect. 2010;16:1494-500.

25. Maltezou HC. Metallo- $\beta$-lactamases in Gram-negative bacteria: introducing the era of pan-resistance? Int J Antimicrob Agents. 2009;33:405e1-7.

26. Brusselaers N, Vogelaers D, Blot S. The rising problem of antimicrobial resistance in the intensive care unit. Ann Intensive Care. 2011:1:47.

\section{Submit your next manuscript to BioMed Central and we will help you at every step:}

- We accept pre-submission inquiries

- Our selector tool helps you to find the most relevant journal

- We provide round the clock customer support

- Convenient online submission

- Thorough peer review

- Inclusion in PubMed and all major indexing services

- Maximum visibility for your research

Submit your manuscript at www.biomedcentral com/submit 